\title{
Generalized Joint Hypermobility in Healthy Female Koreans: Prevalence and Age-Related Differences
}

\author{
Ji-Won Kwon, $\mathrm{MD}^{1}$, Won-Jae Lee, $\mathrm{MD}^{1}$, Si-Bog Park, MD², Mi Jung Kim, MD², \\ Seong Ho Jang, $\mathrm{MD}^{2}$, Chang Kweon Choi, $\mathrm{MD}^{1}$

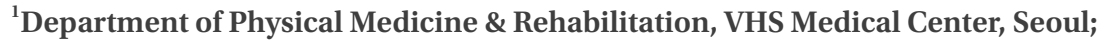 \\ ${ }^{2}$ Department of Rehabilitation Medicine, Hanyang University College of Medicine, Seoul, Korea
}

Objective Objective To evaluate the prevalence of generalized joint hypermobility (GJH) in healthy female Koreans and to determine whether the degree of GJH differs between children and adults.

Methods Two groups of females were enrolled, a group of girls from an elementary school $(n=404)$ and women from a call center $(n=266)$. GJH was diagnosed using the Beighton score, which is composed of an evaluation of bilateral knees, elbows, thumbs, and fifth fingers as well as thoracolumbar joint. The GJH and localized hypermobility of each joint was compared between the two groups, and the pattern of hypermobility according to age and dominant hand was investigated.

Results Total prevalence of GJH was $50.0 \%$ (335/750), and it was more frequently observed in the group of girls $(58.9 \%, 238 / 404)$ than women $(36.5 \%, 97 / 266)$. The degree of GJH expressed in terms of Beighton score was inversely correlated with age $(\mathrm{p}<0.05)$. Significant differences in localized hypermobility of the thumb and fifth finger were found between the two groups and were postulated as the cause for the decline in GJH with age. The pattern of decreased mobility proportional to aging differed between the two joints. Decreased mobility occurred equally on both sides of the thumb but was biased toward the fifth finger of the dominant side (mostly the right). Conclusion The female Koreans appeared to have a high prevalence of GJH. The incidence of GJH decreased as age increased as a result of decreased mobility of the fifth finger on the dominant side.

Keywords Joint hypermobility, Beighton score, Dominant hand, Stiff joint

Received August 1, 2013; Accepted August 23, 2013

Corresponding author: Won-Jae Lee

Department of Physical Medicine \& Rehabilitation, Veterans Health Service Medical Center, 53 Jinhwangdoro 61-gil, Gangdong-gu, Seoul 134-791, Korea

Tel: +82-2-2225-1497, Fax: +82-2-2225-1579, E-mail: braddom@nate.com

@ This is an open-access article distributed under the terms of the Creative Commons Attribution Non-Commercial License (http://creativecommons. org/licenses/by-nc/3.0) which permits unrestricted noncommercial use, distribution, and reproduction in any medium, provided the original work is properly cited.

Copyright $\odot 2013$ by Korean Academy of Rehabilitation Medicine

\section{INTRODUCTION}

Joint hypermobility, a condition in which a joint stretches beyond the normal range of motion (ROM), is classified into single-joint or generalized subtypes [1]. Generalized joint hypermobility (GJH) is associated with inherited connective tissue disorders in children, musculoskeletal injuries in athletes, and rheumatic diseases in adults $[2,3]$. Controversy persists about whether asymptomatic GJH is pathologic in nature, particularly in chil- 
dren $[1,4,5]$.

GJH is commonly diagnosed using the Beighton hypermobility scoring system, the most widely used screening test for hypermobility $[1,6]$. Using this method, various reports have examined the prevalence of GJH in different ethnicities, sexes, ages, and body sides. GJH is more common among West Africans, females, and the nondominant side than among other ethnicities, males, and the dominant side, respectively [2,4,7-9]. However, little is known about the prevalence of GJH in Koreans [10].

The prevalence of GJH has been suggested to decrease with age in children $[2,6]$; however, some controversy remains concerning the decline in joint mobility with age $[1,11]$. Moreover, few studies have examined differences in joint mobility in children vs. adults. Furthermore, whether the use of the adult Beighton cutoff score, generally 4 points, in children is appropriate remains to be clarified $[5,6]$.

The present study was conducted to examine the prevalence of GJH in healthy East Asians and to determine whether the degree of GJH differs between children and adults. A comprehensive analysis was performed to investigate localized hypermobility in each joint and compare the side-by-side differences. Subjects were confined to the Korean race and female sex to minimize variations related to ethnicity and sex.

\section{MATERIALS AND METHODS}

\section{Subjects}

Two groups of females were enrolled from March to September 2008, a group of girls from an elementary school and a group of women from a directory assistance call center. All 491 female prepubertal girls from the first to sixth grades in an elementary school in Seoul were included in the study. Eighty-seven girls were excluded for musculoskeletal pain, history of fracture, history of menarche, and history of family diseases. As a result, 404 healthy students were included. We included 266 of 383 healthy female workers from a single call center who had no specific complaints or history of musculoskeletal injuries. This study was reviewed and approved by the local ethics committee.

\section{Methods}

A Beighton cutoff score was used to determine the presence of GJH [12-14] (Table 1). Nine items are scored based on an ordinal scale of $0-9$, with a higher score representing greater joint mobility. Each individual item was scored using a nominal scale in which " 1 " represents a positive sign and " 0 " represents a negative sign. All measures were obtained bilaterally using a goniometer, with the exception of trunk flexion. A threshold cutoff point of 4 of 9 was used to categorize participants with GJH, as described previously $[11,12]$.

To determine the Beighton score, the subjects were asked to relax their muscles as much as possible, and their joints were then moved through their ROM without evoking pain (Fig. 1). A passive ROM was used to standardize and make the measurements less dependent on the subjects' notion of a full ROM, particularly the girls. Background information about the subjects, including age, dominant hand, and employment duration was obtained using a questionnaire.

We investigated whether the Beighton score significantly differed between the groups of girls and women. We determined the localized score for each joint in cases of a significant difference to determine which joint contributed to the significant difference in total score.

\section{Statistical analysis}

All statistical analyses were performed using SPSS ver.

Table 1. Characteristics of subjects $(n=8)$

\begin{tabular}{|lc}
\hline \multicolumn{1}{c}{ Criteria } & Score \\
\hline Forward flexion of trunk, so that the palms rest easily on the floor, with knees straight & 1 \\
\hline Hyperextension knee $>10^{\circ}$ (each knee) & 2 \\
\hline Hyperextension elbow $>10^{\circ}$ (each elbow) & 2 \\
\hline Passive apposition of the thumb to the flexor aspect of the forearm & 2 \\
\hline Passive hyperextension of the fifth finger joint $\geq 90^{\circ}$ & 2 \\
\hline Maximum possible score & 9 \\
\hline
\end{tabular}

Generalized joint hypermobility is diagnosed based on a score $\geq 4$. 

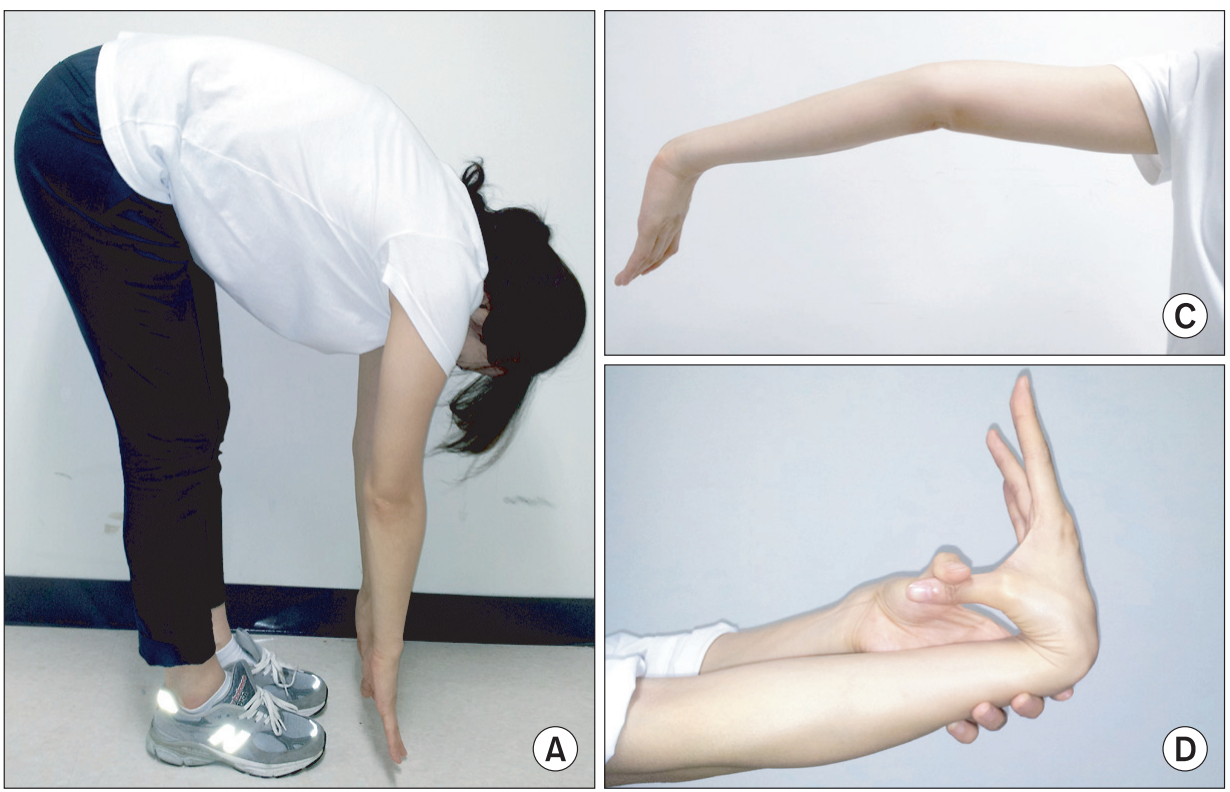

(A)
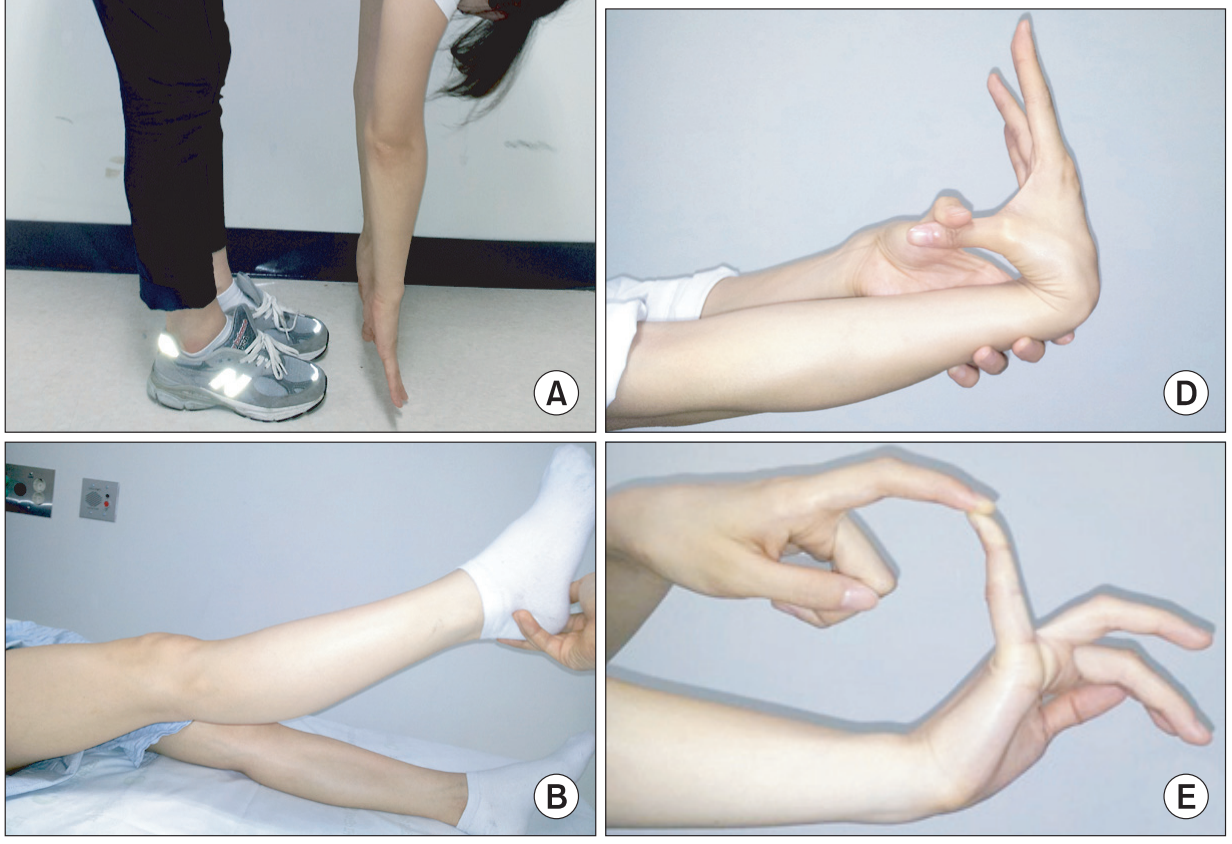

Fig. 1. Assessment using the Beighton hypermobility scoring system: (A) forward flexion of the trunk with the knees straight so that the palms of the hands rest easily on the floor, (B) hyperextension of the knee beyond $10^{\circ}$, (C) hyperextension of the elbow beyond $10^{\circ}$, (D) passive apposition of the thumb to the flexor aspects of the forearm, and (E) passive dorsiflexion of the fifth fingers beyond $90^{\circ}$. (A) was scored 1 point, and (B), (C), (D), and (E) were scored 2 points on both sides.
17.0 for Windows (SPSS Inc., Chicago, IL, USA). First, a descriptive analysis was performed. Differences in the Beighton scores and percentages of GJH between the two groups were tested for significance using the t-test or chisquare test as appropriate. The t-test was used to compare differences in localized hypermobility of each joint, whereas Spearman correlation coefficient was used to evaluate the correlation between the Beighton score and several other factors including age and employment duration. The chi-square test was used to test independence or determine the kappa index. Statistical significance was set at a $\mathrm{p}=0.05$ for all tests.

\section{RESULTS}

In the group of girls, 404 subjects (age, 6-12 years) were included in the study, the mean (standard deviation [SD]) age was 9.1 (1.7) years. In the group of women, $266 \mathrm{fe}$ male workers (age, $24-50$ years) were included. The mean (SD) age was 32.0 (5.1) years, and the mean employment duration was 4.5 (3.1) years. A total of 374 girls (92.6\%) and 257 women (96.6\%) were right-handed, indicating a significantly higher percentage in the group of women. A significant difference in mean Beighton score was found between the groups of girls and women (3.99 [2.32] vs. 2.87 [2.07], $\mathrm{p}<0.05)$. A total of 238 girls $(58.9 \%)$ and 97 women (36.5\%) had GJH. The percentage of GJH, defined as a score $\geq 4$, was significantly higher in the group of girls than that in the group of women (Table 2). The Beighton score was significantly inversely correlated with age in the groups of girls and women, the correlation coefficients $(\mathrm{R})$ were $-0.165(\mathrm{p}=0.001)$ and $-0.143(\mathrm{p}=0.029)$, respectively. However, no correlation was found between the Beighton score and employment duration in the group of women.

Each localized score was compared by joint to investigate the difference in total Beighton score between the two groups. The right and left side scores were added. Significantly higher scores in the thumbs and fifth fingers were noted in the group of girls than in the group of women $(p<0.05)$. The mean (SD) scores of the thumbs 
Table 2. Subjects' general characteristics

\begin{tabular}{|lcc|}
\hline \multicolumn{1}{|c}{ Characteristic } & Group I (n=404) & Group II (n=266) \\
\hline Age (yr) & $9.1 \pm 1.7$ & $32.0 \pm 5.1^{*}$ \\
\hline Range & $6-12$ (girls) & $24-50$ (women) \\
\hline Right-handedness & $374(92.6)$ & $257(96.6)^{*}$ \\
Tenure of service (yr) & - & $4.5 \pm 3.1$ \\
\hline Beighton score & $3.99 \pm 2.32$ & $2.87 \pm 2.07^{*}$ \\
\hline Generalized joint hypermobility & $238(58.9)$ & $97(36.5)^{*}$ \\
\hline
\end{tabular}

Values are expressed as mean \pm standard deviation or number (\%).

${ }^{*} \mathrm{p}<0.05$.

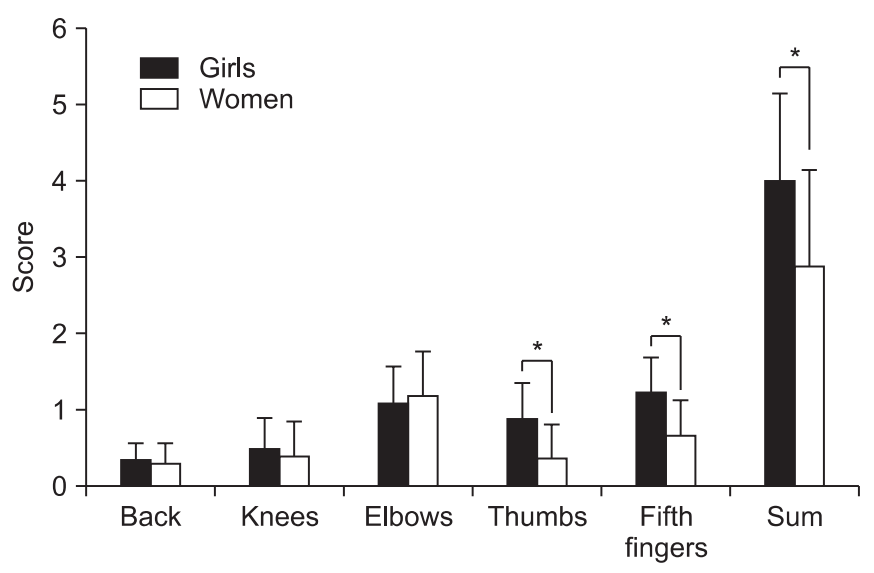

Fig. 2. Comparisons of the localized joint scores and total Beighton scores between the groups of girls and women. Bilateral scores were added for each joint except for the back. The scores of the thumbs and fifth fingers as well as the total score were significantly higher in the group of girls than those in the group of women. ${ }^{*} \mathrm{p}<0.05$ using the t-test.

were $0.88(0.47)$ and $0.36(0.35)$ in the group of girls and women, respectively. The mean (SD) scores of the fifth fingers were $1.23(0.46)$ and $0.66(0.47)$ in the group of girls and women, respectively. No significant differences in Beighton score were found regarding the back, knee, or elbow joints (Fig. 2).

We examined the pattern of hypermobility in the thumbs and fifth fingers between the groups of girls and women using a pie chart (Fig. 3). To reflect bilaterality of hypermobility, the patterns were divided into four groups-A, bilateral nonhypermobility; B, left-sided hypermobility; C, right-sided hypermobility; and D, bilateral hypermobility. First, using the independence test, we confirmed that patterns A-D were significantly different between the two groups for both joints $(\mathrm{p}<0.001)$.

In the case of the thumb, the group of girls had the following patterns: A in 208 (51.49\%), B in 15 (3.71\%), C in $23(5.69 \%)$, and D in 158 girls $(39.11 \%)$. The group of women had the following patterns: A in 210 (78.95\%), B in 6 (2.26\%), C in 10 (3.76\%), and D in 40 women (15.04\%). The group of women had a higher percentage of pattern $A$ and a lower percentage of pattern $D$ in the thumbs compared with the group of girls. In the case of the fifth finger, 140 (34.65\%), 27 (6.68\%), 5 (1.24\%), and 232 girls (57.43\%) had patterns A, B, C, and D, respectively, whereas $139(52.26 \%), 66(24.81 \%), 12(4.51 \%)$, and 49 women (18.42\%) had patterns A, B, C, and D, respectively. The percentages of patterns $A, B$, and $C$ increased, and the percentage of pattern $D$ decreased in the fifth fingers of the women compared with the girls. The fifth finger had a higher increase in the frequency of pattern B compared with the thumb.

A significant agreement was found between the hypermobile fifth fingers and the nondominant hand, mainly the left side, in the group of women for the discrepant patterns B and C (kappa $=0.133, p=0.018)$. Agreement was also observed in the group of girls, though it was statistically insignificant (kappa $=0.216, p=0.167$ ).

\section{DISCUSSION}

We investigated the prevalence of GJH in healthy female Koreans and determined whether an age-related difference existed. We demonstrated a $50.0 \%$ prevalence of GJH in Korean females (58.9\% of the girls and $36.5 \%$ of the women). We found significantly decreased hypermobility with increasing age, the difference mainly stemming from the loss of localized hypermobility in the fifth 

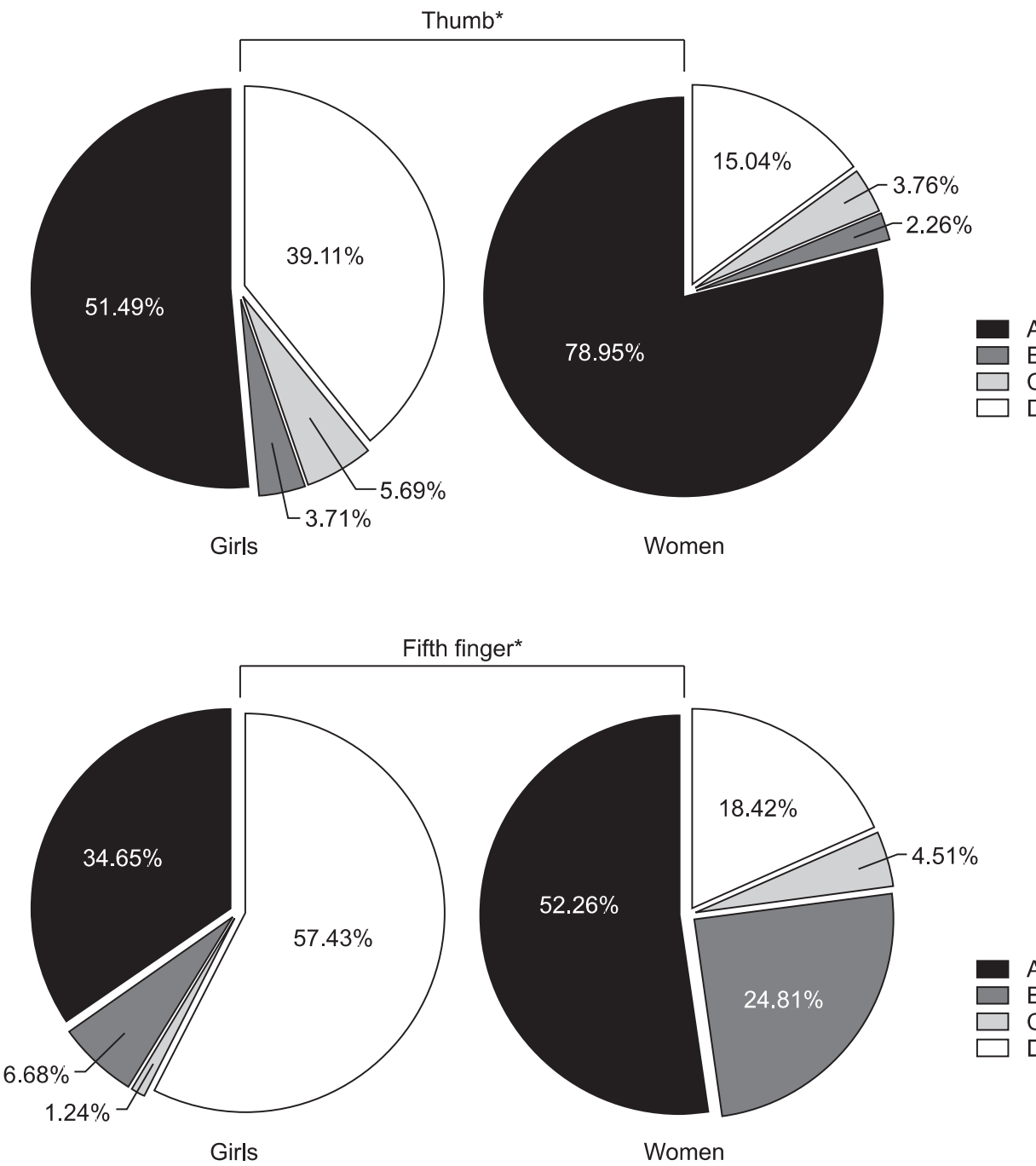

Fifth finger*

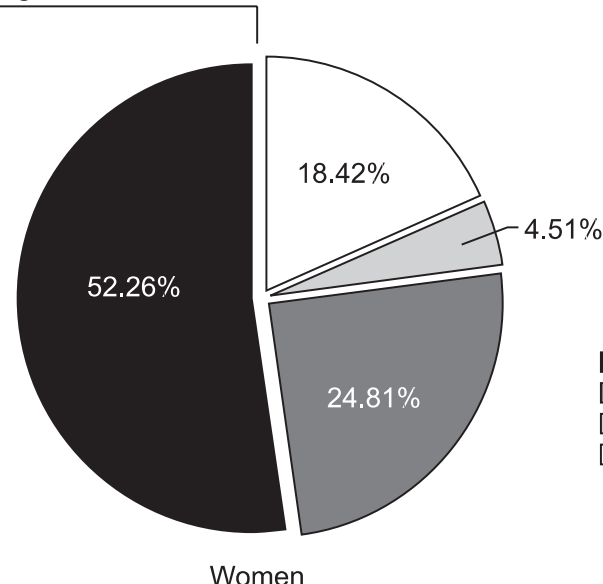

Fig. 3. Comparison of the bilaterality of hypermobility of the thumbs and fifth fingers between the groups of girls and women. The four patterns of bilaterality are as follows in counterclockwise order: pattern A, bilateral nonhypermobility; pattern $\mathrm{B}$, left-sided hypermobility; pattern $\mathrm{C}$, rightsided hypermobility; and pattern D, bilateral hypermobility. The percentage of pattern A was greatly increased in the thumbs of the women, whereas that of pattern D was correspondingly decreased compared with that in the thumbs of the girls. However, the percentage of pattern B was greatly increased and that of pattern D correspondingly decreased in the fifth fingers of the women, compared with that in the fifth fingers of the girls. ${ }^{*} \mathrm{p}<0.05$ by chi-square test. finger of the dominant side as one ages.

Our results correspond well with those of earlier studies, which reported that GJH decreases with age in children $[6,8,15]$. Our study confirmed that GJH decreased with age in adults as well and revealed an age-related difference between prepubertal girls and adult women. Localized hypermobility of the thumbs and fifth fingers decreased significantly in the women compared with the girls; however, the decreasing patterns were not identical. The decrease in mobility with aging originated from the loss of bilateral hypermobility in the thumbs, whereas the decreased hypermobility on the right side was the main cause in the case of the fifth fingers, a finding that was consistent with those of studies suggesting reduced mobility on the dominant side $[1,6,16]$. Our study showed a GJH prevalence of $50 \%$, a finding that was different from those of other ethnicities (19.5\% of Dutch and $57.0 \%$ of Nigerians) [4,7]. This is the first study to report on the prevalence of asymptomatic GJH in East Asians. We postulate that Koreans have greater joint mobility than Caucasians but less joint mobility than West Africans.

GJH is associated with localized joint pain, sport-specific injuries, and rheumatic diseases in adults $[10,17,18]$. $\mathrm{GJH}$ is often asymptomatic and poorly recognized in children [1], but subclinical GJH is believed to be associated with inherited collagen disorders, such as Marfan and Ehlers-Danlos syndromes [2]. An effective assessment tool is needed for proper screening and management of GJH. However, a standard cutoff Beighton score to diagnose GJH in children has yet to be confirmed. Our findings indicate that the percentage of GJH in the group of girls decreased when the cutoff point $\geq 4$ was changed to $\geq 5$, demonstrating a decrease from $58.9 \%$ to $42.3 \%$. Based on our finding regarding the significant decline 
of GJH in proportion to age, it seems to be reasonable to set 5 points as the cutoff value of GJH in children, which is 1 point higher than that in adults. These findings correspond to those of earlier studies $[1,5,6]$. Considering the relatively high prevalence of asymptomatic GJH in children, setting 5 points as the standard cutoff score may increase specificity, suggesting that the Beighton hypermobility scoring system is an efficient screening tool for GJH.

An important finding of our study was that the loss of localized hypermobility in the fifth finger of dominant side, mostly the right, was observed with aging, which mainly contributed to the decreased prevalence of GJH in the women vs. the girls in our study. This decreased mobility is presumed to be attributed to the social and economic features of the Korean society and to anatomical causes. First, degenerative changes in collagen levels in the articular cartilage and skin lead to reduced joint mobility with increasing age $[19,20]$. Furthermore, Schweitzer [21] postulated that increased tension in the volar plate and flexor tendon in the fingers could limit ROM, which is in close agreement with our findings. Second, there is a predominance of right-handedness in Korea at a significantly higher incidence rate than that in the West and continued enforcement of the use of the right hand as a child grows [22]. The amount of time individuals spend using Internet-related devices has been steadily increasing worldwide, including in Korea [23]. In particular, because the dominant hand is used to grip the mouse, the function of the little finger can be limited to a supportive role compared with the active use of the thumb for gripping and the index finger for clicking; therefore, the restriction is postulated as being the cause of decreased mobility in the fifth finger.

These findings are coincident with those of earlier studies that reported that the fourth and fifth fingers are less functional than the other three fingers due to the differential peripheral motor control in the dominant hand $[16,24,25]$. Molenaar et al. [26] emphasized the individual evaluation of each localized joint rather than the overall hand function, such as grip power, almost identical to our results. We propose that it is important to consider the physiologically increased generalized hypermobility and decreasing tendency of dominant-hand mobility during the evaluation and follow-up of prepubertal children.

The present study had some limitations. First, it includ- ed only females. Second, the applicability of the Beighton score was confined to some joints, so other joints could not be analyzed for hypermobility. Further cohort studies including the male sex and other evaluation tools are needed to evaluate whether the pattern of joint hypermobility in children changes throughout the life cycle.

In conclusion, we demonstrated that female Koreans in our study had a high prevalence of GJH. The incidence of GJH decreased as age increased, as a result of the decreased mobility of the fifth finger on the dominant side.

\section{CONFLICT OF INTEREST}

No potential conflict of interest relevant to this article was reported.

\section{REFERENCES}

1. Smits-Engelsman B, Klerks M, Kirby A. Beighton score: a valid measure for generalized hypermobility in children. J Pediatr 2011;158:119-23.

2. Wolf JM, Cameron KL, Owens BD. Impact of joint laxity and hypermobility on the musculoskeletal system. J Am Acad Orthop Surg 2011;19:463-71.

3. Guma M, Olive A, Roca J, Forcada J, Duro JC, Holgado S, et al. Association of systemic lupus erythematosus and hypermobility. Ann Rheum Dis 2002;61:1024-6.

4. Rikken-Bultman DG, Wellink L, van Dongen PW. Hypermobility in two Dutch school populations. Eur J Obstet Gynecol Reprod Biol 1997;73:189-92.

5. Leone V, Tornese G, Zerial M, Locatelli C, Ciambra R, Bensa $\mathrm{M}$, et al. Joint hypermobility and its relationship to musculoskeletal pain in schoolchildren: a cross-sectional study. Arch Dis Child 2009;94:627-32.

6. van der Giessen LJ, Liekens D, Rutgers KJ, Hartman A, Mulder PG, Oranje AP. Validation of Beighton score and prevalence of connective tissue signs in 773 Dutch children. J Rheumatol 2001;28:2726-30.

7. Birrell FN, Adebajo AO, Hazleman BL, Silman AJ. High prevalence of joint laxity in West Africans. Br J Rheumatol 1994;33:56-9.

8. Jansson A, Saartok T, Werner S, Renstrom P. General joint laxity in 1845 Swedish school children of different ages: age- and gender-specific distributions. Acta Paediatr 2004;93:1202-6.

9. Al-Rawi ZS, Al-Aszawi AJ, Al-Chalabi T. Joint mobil- 
ity among university students in Iraq. Br J Rheumatol 1985;24:326-31.

10. Hudson N, Fitzcharles MA, Cohen M, Starr MR, Esdaile JM. The association of soft-tissue rheumatism and hypermobility. Br J Rheumatol 1998;37:382-6.

11. Czaprowski D, Kotwicki T, Pawlowska P, Stolinski L. Joint hypermobility in children with idiopathic scoliosis: SOSORT award 2011 winner. Scoliosis 2011;6:22.

12. Konopinski MD, Jones GJ, Johnson MI. The effect of hypermobility on the incidence of injuries in elitelevel professional soccer players: a cohort study. Am J Sports Med 2012;40:763-9.

13. Beighton P, Solomon L, Soskolne CL. Articular mobility in an African population. Ann Rheum Dis 1973;32:413-8.

14. Grahame R, Bird HA, Child A. The revised (Brighton 1998) criteria for the diagnosis of benign joint hypermobility syndrome (BJHS). J Rheumatol 2000;27:1777-9.

15. Adib N, Davies K, Grahame R, Woo P, Murray KJ. Joint hypermobility syndrome in childhood: a not so benign multisystem disorder? Rheumatology (Oxford) 2005;44:744-50.

16. Gunal I, Kose N, Erdogan O, Gokturk E, Seber S. Normal range of motion of the joints of the upper extremity in male subjects, with special reference to side. J Bone Joint Surg Am 1996;78:1401-4.

17. Kim HJ, Yeom JS, Lee DB, Kang KT, Chang BS, Lee $\mathrm{CK}$. The association of benign joint hypermobility with spinal segmental motion and its clinical implication in active young man. Spine (Phila Pa 1976) 2013 Mar 7 [Epub]. http://dx.doi.org/10.1097/
BRS.0b013e31828ffa15.

18. Pacey V, Nicholson LL, Adams RD, Munn J, Munns CF. Generalized joint hypermobility and risk of lower limb joint injury during sport: a systematic review with meta-analysis. Am J Sports Med 2010;38:1487-97.

19. Ridge MD, Wright V. The ageing of skin: a bio-engineering approach. Gerontologia 1966;12:174-92.

20. Verzijl N, DeGroot J, Oldehinkel E, Bank RA, Thorpe SR, Baynes JW, et al. Age-related accumulation of Maillard reaction products in human articular cartilage collagen. Biochem J 2000;350 Pt 2:381-7.

21. Schweitzer G. Laxity of metacarpophalangeal joints of fingers and interphalangeal joint of the thumb: a comparative inter-racial study. S Afr Med J 1970;44:246-9.

22. Kim SI, Kim WS, Cho KJ. The type of handedness and correlation analysis of handedness assessment items on university students in Korea. Korean J Phys Anthropol 2008;21:245-53.

23. Greenstein S, McDevitt, R. Measuring the broadband bonus in thirty OECD countries. Paris: OECD Publishing; 2012.

24. McManus IC, Kemp RI, Grant J. Differences between fingers and hands in tapping ability: dissociation between speed and regularity. Cortex 1986;22:461-73.

25. Radwin RG, Oh S, Jensen TR, Webster JG. External finger forces in submaximal five-finger static pinch prehension. Ergonomics 1992;35:275-88.

26. Molenaar HM, Selles RW, Willemsen SP, Hovius SE, Stam HJ. Growth diagrams for individual finger strength in children measured with the RIHM. Clin Orthop Relat Res 2011;469:868-76. 